\title{
International Asset Pricing with Recursive Preferences
}

\author{
Riccardo Colacito
}

Mariano M. Croce*

\begin{abstract}
Focusing on US and UK, we document that both the Backus and Smith (1993) finding, concerning the low correlation between consumption differentials and exchange rates, and the forward-premium anomaly, concerning the tendency of high interest rate currencies to appreciate, have become more severe through time. After accounting for different capital mobility regimes, we show that these anomalies turn into general equilibrium regularities in a two-country and two-good economy with Epstein and Zin (1989) preferences, frictionless markets, and highly correlated long-run endowment growth prospects.
\end{abstract}

JEL classification: C62; F31; G12.

First Draft: February 14, 2008. This draft: February 9, 2012.

${ }^{*}$ Both authors are affiliated with the University of North Carolina at Chapel Hill, Kenan-Flagler School of Business. We would like to thank an anonymous referee, Amir Yaron, Ravi Bansal, Tom Sargent, Andreas Stathopoulos (our discussant at the 2011 SFS Cavalcade), Chris Telmer (our discussant at the 2011 WFA Meeting), Stijn Van Nieuwerburgh, and Adrien Verdelhan for their invaluable feedback. We also thank the seminar participants at the 2009 UNC Jackson-Hall Conference, the 2011 WFA meetings, the 2011 SFS Finance Cavalcade Conference, CREATE Business School, NYU-Stern, and Wharton. Some of the work on this paper was completed while Colacito was visiting the Stern Business School and Croce was visiting the Wharton Business School. This research was funded in part by The Jefferson-Pilot Faculty Development Fund. All remaining errors are our own. 


\section{Introduction}

Two of the best established empirical facts in international finance are the tendency of high interest rate currencies to appreciate (forward premium anomaly), and the lack of correlation between consumption growth differentials and exchange rate movements (Backus and Smith anomaly). The first one contradicts the logic of the basic Uncovered Interest Rate Parity (UIP) relationship, while the second one is at odds with the condition impelled by any model with standard time-additive preferences and complete markets.

A less well known aspect is the dramatic change of the behavior of these empirical regularities before and after the early 1970s. Focusing on real data from the US and UK, in the left panel of figure 1 we document that the UIP regression coefficient is remarkably close to unity in the pre-1970 sample and then it sharply falls right after 1970. In the right panel of figure 1, we depict the time-varying correlation of real consumption growth differentials and real exchange rate movements. Similarly to the left panel, this correlation experiences a sizable and statistically significant decline right after 1970 .

These empirical findings raise at least two relevant questions. How can we explain the marked departure from the theoretical relationships in the post-1970 sample? Furthermore: how do we justify the drop in the regression coefficient and in the correlation across the two sub-samples? Providing a coherent answer to these questions has traditionally been a challenge for most general equilibrium asset pricing models.

To explain these dynamics, we propose a general equilibrium model featuring three crucial elements: (i) preference for early resolution of uncertainty; (ii) existence of highly correlated international long-run components in output, and (iii) a substantial increase in capital mobility going from the pre- to the post-1970 sample. After explaining in detail the role of each element for the dynamics of both international quantities and prices, we show that our model replicates a wide set of international moments both in the pre- and in the post-1970 sample. To the best of our knowledge, our model offers the first unified framework able to quantitatively replicate a wide array of international stylized facts across different regimes of financial integration.

We start by characterizing international trade and asset prices in a frictionless two 

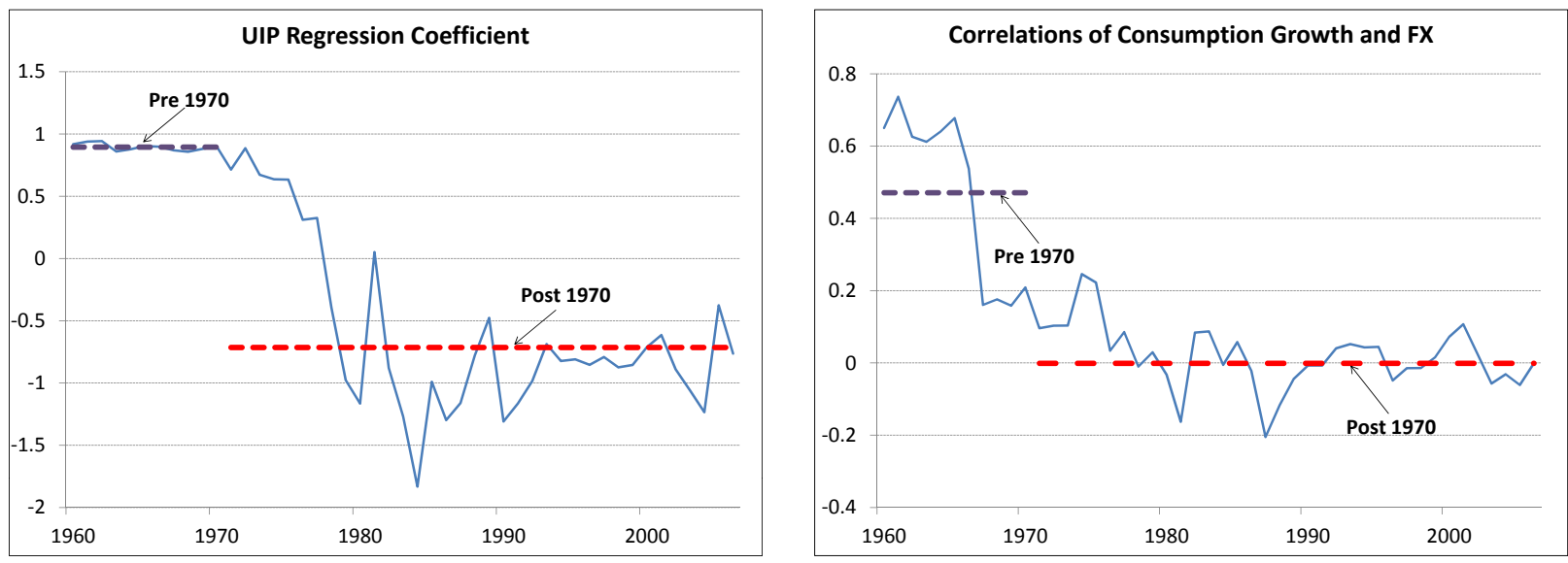

FIG. 1 - UIP coefficients and Backus and Smith correlation across regimes. The left panel reports the UIP coefficient estimated using a rolling sample of 30 years. The right panel shows the correlation between consumption growth differentials and exchange rate growth.

country-two good economy in which agents have Epstein and Zin (1989) preferences and the growth rates of their endowments feature slowly moving predictive factors (long-run risks). We assume that markets are complete both domestically and internationally and compare this setup to the data for the post-1970 sample, a period of substantial financial integration across all major industrialized countries (among others see, Taylor (1996), Quinn (1997) and Obstfeld (1998)).

To characterize the trading arrangement of our agents, we generalize the methods developed by Colacito and Croce (2010a) in an i.i.d. risk-sensitive environment to the case in which the intertemporal elasticity of substitution (IES) differs from one and growth rates of the endowments are predictable. As in Colacito and Croce (2010a), our agents dynamically adjust their share of world consumption in a counter-cyclical fashion in order to trade-off expected future utility for a reduction of future utility risk. We document that the utility mean-variance frontier of each agent becomes steeper when the IES increases and when endowments feature long-run uncertainty. In particular, we show that the endogenous time-varying volatility of continuation utilities generated by our risk-sharing scheme satisfies the Fama (1984)'s conditions for the resolution of the forward premium anomaly, only when the IES is greater than one. 
We show that in a regime of financial integration, the role of long-run risk is twofold. On the one hand it amplifies utility risk and risk-sharing motives. On the other hand, it breaks the perfect correlation between short-run consumption differentials and exchange rate growth and contributes to the resolution of the Backus-Smith anomaly.

This can be explained, for example, by focusing on the realization of good long-run news to the supply of the home good. The continuation utility of the home country increases as she anticipates more consumption for the long-run. Since agents with recursive preferences are averse to utility risk in addition to consumption risk, the increase in future utility reduces the intertemporal marginal rate of substitution of the home country. Such decline has two effects: (i) by no arbitrage, the home currency depreciates in anticipation of a higher long-run supply of the home good, and (ii) resources are optimally reallocated from the home country (low marginal utility country) to the foreign one (high marginal utility country). Since long-run news do not change short-run endowments, this reallocation produces an increase in foreign consumption growth and a decrease in home consumption. Hence, consumption growth differential and exchange rate growth move in opposite directions.

This novel theoretical result introduces a currency-based lower bound on the IES that complements the lower-bound found by Bansal and Yaron (2004) focusing on equity predictability. Interestingly, our model also sets an upper bound on this elasticity. As the IES gets larger, agents are so adverse to utility risk that they are willing to make the risk-sharing scheme more aggressive in order to bear less utility risk. In this case, the endogenous reduction of future utility risk promoted by trade dampens the impact of long-run endowment shocks on consumption growth, ultimately reducing the ability of the model to reproduce the Backus-Smith anomaly. We find that values of IES is a neighborhood of 1.5-2 can closely match the data.

When focusing on the pre-1970 period, we assume that the two countries trade only goods, but cannot exchange international assets and borrow from (lend to) each other. In the language of Cole and Obstfeld (1991), we are in a regime of financial autarky. In this setup there is no room for intertemporal risk-sharing. Risk sharing consists only in smoothing short-run consumption by exchanging goods whose value is perfectly balanced in every period and state of the world. Since this implies that the share of world consumption of each country is fixed, the utility mean-variance trade-off is inactive and allocations look identical to those obtained with standard time-additive 
preferences. In this regime, the model predicts that the UIP regression coefficient is close to one and the Backus-Smith correlation is exactly equal to one. When we compare the data in the pre- and post-1970 sample to our model with and without financial integration, the results are broadly consistent.

Furthermore, in financial autarky the exchange rate growth is just a reflection of the difference in the short-run growth rate of the endowments of the two goods. Since endowments are smooth, exchange rate is smooth as well. With financial integration, instead, international trading of securities produces a substantial amount of pressure on currency making it twice as volatile. Overall, our model captures almost entirely the increase in the volatility of the real exchange rate observed the post-1970 data.

We also look at a larger set of moments to further validate our model. We show that recursive preferences and long-run risks allow an otherwise standard general equilibrium model to simultaneously explain a very large number of international finance facts. This includes the large volatility of stochastic discount factors, and the amount of persistence, volatility, and cross-country correlation of international consumption and output growth rates across samples. This study, therefore, differs from our previous work for the attention that we devote to generalized Epstein and Zin (1989) preferences, long-run risks, and, most importantly, for our comparative study across capital mobility regimes.

Last but not least, we estimate the conditional responses of consumption growth differentials between US and UK to long-run endowment shocks in the post-1970 sample and we find results strongly consistent with our risk-sharing mechanism. We find that consumption growth in the US tends to decline upon the realization of either short- or long-run good news to US output. These findings are stronger when we use both international prices and quantities to identify US and UK long-run components. The paper is organized as follows. The next section describes the empirical facts that motivate our analysis. In section 3 and 4, we describe our data and economy, respectively. In section 5 we focus on the equilibrium with complete markets. Section 6 describes the equilibrium with financial autarky. Section 7 concludes. 


\section{Empirical background: country choice}

We focus on the US and the UK for a number of reasons both practical and historical. First of all, the identification of highly persistent time series, such as the long-run components analyzed in the model, requires as long a sample as possible. From this stand-point, the US and UK are probably the best examples of countries with a long history of accurate consumption, import, and export data. Also, the US and UK have become increasingly integrated during the postWorld War II period, as documented by Taylor (1996), Quinn (1997), and Obstfeld (1998) among others. This enables us to make a comparison between times of relatively different degrees of financial integration.

Our common sample covers the years from 1929 to 2006, and we look at two separate sub-samples: pre- and post-1970. The choice of the two sub-samples is motivated by the analysis of Obstfeld (1998), that suggests that there has been an increasing financial integration between US and UK, starting in the late 1960s-early 1970s. All data sources are specified in $\underline{\mathrm{A}}$.

\section{The economy: preferences and endowments}

The economy consists of two countries, home $(h)$ and foreign $(f)$, and two goods, $X$ and $Y$. Agents' preferences are defined over consumption aggregates of the two goods at each history as follows.

Consumption aggregate. Let $x_{t}^{i}$ and $y_{t}^{i}$ denote the consumption of good $X$ and good $Y$ in country $i \in\{h, f\}$ at date $t$. Let $\alpha \in(0,1)$. The consumption aggregates in the two countries are:

$$
C_{t}^{h}=\left(x_{t}^{h}\right)^{\alpha}\left(y_{t}^{h}\right)^{1-\alpha} \quad \text { and } \quad C_{t}^{f}=\left(x_{t}^{f}\right)^{1-\alpha}\left(y_{t}^{f}\right)^{\alpha}
$$

respectively. The parameter $\alpha$ captures the degree of bias of the consumption of each representative agent. In what follows we assume that the home country is endowed with good $X$, while the foreign country is endowed with good $Y$. Allowing $\alpha$ to be 
greater than $1 / 2$, therefore, is equivalent to assume consumption home bias 1 This assumption is standard in the literature (among others, see Lewis (1999)).

Preferences. As in Epstein and Zin (1989), agents' preferences are recursive but non-time separable:

$$
U_{t}^{i}=\left[(1-\delta) \cdot\left(C_{t}^{i}\right)^{1-1 / \psi}+\delta E_{t}\left[\left(U_{t+1}^{i}\right)^{1-\gamma}\right]^{\frac{1-1 / \psi}{1-\gamma}}\right]^{\frac{1}{1-1 / \psi}}, \quad \forall i \in\{h, f\} .
$$

The coefficients $\gamma$ and $\psi$ measure the relative risk aversion (RRA) and the intertemporal elasticity of substitution (IES), respectively. The implied pricing kernels with respect to the consumption bundles are:

$$
M_{t+1}^{i}=\delta\left(\frac{C_{t+1}^{i}}{C_{t}^{i}}\right)^{-\frac{1}{\psi}}\left(\frac{U_{t+1}^{i 1-\gamma}}{E_{t}\left[U_{t+1}^{i 1-\gamma}\right]}\right)^{\frac{1 / \psi-\gamma}{1-\gamma}} .
$$

The main departure from the constant relative risk aversion case often analyzed in the literature lies in the fact that these preferences allow agents to be risk averse in future utility in addition to future consumption. The extent of such utility risk aversion depends on the preference for early resolution of uncertainty measured by $\gamma-1 / \psi>0$. To better highlight this feature of the preferences, we focus on the ordinally equivalent transformation

$$
V_{t}=\frac{U_{t}^{1-1 / \psi}}{1-1 / \psi}
$$

and document in $\mathrm{B}$ that

$$
\begin{aligned}
V_{t} & =\frac{C_{t}^{1-1 / \psi}}{1-1 / \psi}+\delta E_{t}\left[V_{t+1}^{1-\theta}\right]^{\frac{1}{1-\theta}} \\
& \approx \frac{C_{t}^{1-1 / \psi}}{1-1 / \psi}+\delta E_{t}\left[V_{t+1}\right]-\frac{\delta}{2} \frac{\theta}{E_{t}\left[V_{t+1}\right]} \operatorname{Var}_{t}\left[V_{t+1}\right],
\end{aligned}
$$

\footnotetext{
${ }^{1}$ In this paper we decentralize the economy assuming the existence of a complete set of ArrowDebreu securities and hence we do not have any direct implications for the home bias in portfolio allocations.
} 
where $\theta \equiv \frac{\gamma-1 / \psi}{1-1 / \psi}$. Note that the sign of $\left(\frac{\theta}{E_{t}\left[V_{t+1}\right]}\right)$ depends on the sign of $(\gamma-1 / \psi)$. When $\gamma=1 / \psi$, the agent is utility-risk neutral and preferences collapse to the standard time additive case. When the agent prefers early resolution of uncertainty, $\gamma>1 / \psi$, the coefficient $\theta$ is positive: continuation utility uncertainty reduces welfare and generates an incentive to trade-off future expected utility, $E_{t}\left[V_{t+1}\right]$, for future utility risk, $\operatorname{Var}_{t}\left[V_{t+1}\right]$. This mean-variance trade-off is a very appealing feature of these preferences and yet one that is otherwise absent when agents have standard time-additive preferences. This trade-off drives international allocations and exchange rate adjustments in our economy with complete markets and it represents the most important element of our analysis. Our study is the first one to fully characterize trade with Epstein and Zin (1989) preferences, a task considered difficult even in recent literature (among others, see ?).

Since there is a one-to-one mapping between utility, $U_{t}^{i}$, and life-time wealth, that is the value of a perpetual claim to consumption, $W_{c, t}^{i}$ :

$$
U_{t}^{i}=\left[(1-\delta)\left(C_{t}^{i}+W_{c, t}^{i}\right)\right]^{\frac{1}{1-1 / \psi}}, \quad \forall i \in\{h, f\}
$$

the optimal risk-sharing scheme can also be interpreted in terms of mean-variance trade-off of wealth. For this reason, in what follows we will use the terms 'wealth' and 'continuation utility' interchangeably.

Endowments. We choose to endow each country with the stochastic supply of its most preferred good ( $X$ for home and $Y$ for foreign). As in Colacito and Croce (2011), endowments are integrated process of order one and they embody predictive variables as follows:

$$
\begin{aligned}
\log X_{t} & =\mu_{x}+\log X_{t-1}+z_{1, t-1}+\varepsilon_{x, t} \\
\log Y_{t} & =\mu_{y}+\log Y_{t-1}+z_{2, t-1}+\varepsilon_{y, t}
\end{aligned}
$$

where $z_{j, t}=\rho_{j} z_{j, t-1}+\varepsilon_{j, t}, \forall j \in\{1,2\}$ and $\xi_{t} \equiv\left[\begin{array}{llll}\varepsilon_{1, t} & \varepsilon_{2, t} & \varepsilon_{x, t} & \varepsilon_{y, t}\end{array}\right] \sim_{i . i . d .} N(\mathbf{0}, \Sigma)$. We abstract from exogenous time-varying volatility in endowments to better quantify the amount of endogenous consumption and asset prices volatility generated by our recursive risk-sharing mechanism with complete markets. By doing so, we provide 
a general equilibrium foundation for the exogenous time-varying consumption risk examined by Colacito (2008) and Bansal and Shaliastovich (2010). We also provide a general equilibrium explanation of the findings obtained by Lustig and Verdelhan (2007), and Lustig, Roussanov and Verdelhan (2011).

\section{Markets' Structures}

In order to understand the impact of market integration on the joint dynamics of international asset prices and quantities, we consider two markets' structures. We take the stand that the pre-1970 sample can be characterized as a regime of portfolio autarky, while the post-1970 sample features instead complete markets. We start by describing the equilibrium under portfolio autarky.

\subsection{Portfolio Autarky}

As in Cole and Obstfeld (1991), portfolio autarky consists in a ban on the trade of international securities. Trade in the goods' market is allowed, but it has to be balanced in every period. Financial markets are complete only within each country, meaning that in each country there is a complete set of state- and date-contingent securities, $A_{t+1}^{h}\left(\zeta^{t+1}\right)$ and $A_{t+1}^{f}\left(\zeta^{t+1}\right)$, which are in zero net supply. The implied budget constraints of the two agents are:

$$
\begin{aligned}
& x_{t}^{h}+p_{t} y_{t}^{h}+\int_{\zeta^{t+1}} A_{t+1}^{h}\left(\zeta^{t+1}\right) Q_{t+1}^{h}\left(\zeta^{t+1}\right)=X_{t} \\
& x_{t}^{f}+p_{t} y_{t}^{f}+\int_{\zeta^{t+1}} A_{t+1}^{f}\left(\zeta^{t+1}\right) Q_{t+1}^{f}\left(\zeta^{t+1}\right)=p_{t} Y_{t} .
\end{aligned}
$$

where $\zeta^{t+1}$ denotes the history of states up and until date $t+1$.

Allocations and Prices. Since no international trade of securities can take place, agents have no room for intertemporal consumption smoothing. In equilibrium, allo- 
cations behave as in the case of standard time-additive preferences:

$$
\begin{aligned}
x_{t}^{h} & =\frac{X_{t}}{1+\frac{1-\alpha}{\alpha} S_{0}}, & x_{t}^{f} & =\frac{X_{t}}{1+\frac{\alpha}{1-\alpha} S_{0}} \\
y_{t}^{h} & =\frac{Y_{t}}{1+\frac{\alpha}{1-\alpha} S_{0}}, & y_{t}^{f} & =\frac{Y_{t}}{1+\frac{1-\alpha}{\alpha} S_{0}},
\end{aligned}
$$

where $S_{0}$ is related to the time-zero relative wealth of the two agents. In what follows, we set $S_{0}=1$, consistently with the symmetric calibration of our model. Given these allocations, consumption growth rates evolve according to:

$$
\begin{aligned}
& \Delta c_{t}^{h, \text { aut }}=\alpha \Delta x_{t}+(1-\alpha) \Delta y_{t} \\
& \Delta c_{t}^{f, \text { aut }}=(1-\alpha) \Delta x_{t}+\alpha \Delta y_{t} .
\end{aligned}
$$

Since financial markets are shut down, the real exchange rate simply reflects the current relative supply of the two goods:

$$
\Delta e_{t}=\Delta x_{t}-\Delta y_{t}
$$

and local state-contingent prices are: $Q_{t+1}^{i}=M_{t+1}^{i} \cdot \frac{C_{x, t+1}^{h}}{C_{x, t}^{h}} \cdot f\left(\xi_{t+1}\right), \quad i \in\{h, f\}$, where $f(\cdot)$ measures the probability density of the shocks embodied in $\xi_{t+1}$.

\subsection{Complete Markets}

At each date, trade occurs in a complete set of one period ahead claims to statecontingent consumption. Financial and goods' markets are assumed to be frictionless. The budget constraints of the two agents can be written as:

$$
\begin{aligned}
& x_{t}^{h}+p_{t} y_{t}^{h}+\int_{\zeta^{t+1}} A_{t+1}^{h}\left(\zeta^{t+1}\right) Q_{t+1}\left(\zeta^{t+1}\right)=A_{t}^{h}+X_{t} \\
& x_{t}^{f}+p_{t} y_{t}^{f}+\int_{\zeta^{t+1}} A_{t+1}^{f}\left(\zeta^{t+1}\right) Q_{t+1}\left(\zeta^{t+1}\right)=A_{t}^{f}+p_{t} Y_{t},
\end{aligned}
$$

where $p_{t}$ denotes the relative price of good $Y$ and good $X$ (the terms of trade), $A_{t}^{i}\left(\zeta^{t}\right)$ denotes country $i$ 's claims to time $t$ consumption of good $X$, and $Q_{t+1}^{h}\left(\zeta^{t+1}\right)$ gives the price of one unit of time $t+1$ consumption of good $X$ contingent on the realization 
of $\zeta^{t+1}$ at $t+1$. In equilibrium, the market for international state contingent claims clears, that is: $A_{t}^{h}+A_{t}^{f}=0, \forall t$.

Allocations. Since markets are complete, we can compute efficient allocations by solving the associated Pareto problem. The planner attaches date 0 nonnegative Pareto weights $\mu^{h}=\mu$ and $\mu^{f}=1-\mu$ to the consumers and chooses the sequence of allocations $\left\{x_{t}^{h}, x_{t}^{f}, y_{t}^{h}, y_{t}^{f}\right\}_{t=0}^{+\infty}$ to maximize

$$
\Lambda=\mu \cdot U_{0}^{h}+(1-\mu) \cdot U_{0}^{f}
$$

subject to the sequence of economy wide feasibility constraints:

$$
\begin{aligned}
x_{t}^{h}+x_{t}^{f} & =X_{t} \\
y_{t}^{h}+y_{t}^{f} & =Y_{t}, \quad \forall t \geq 0,
\end{aligned}
$$

where the state-dependent notation is omitted for the sake of clarity. In characterizing the equilibrium, we follow Anderson (2005) and formulate the problem using time-varying pseudo-Pareto weights. This technique enables us to take into account the non-separability of the utility functions. We show in Appendix $\mathrm{C}$ that the first order necessary conditions imply the following allocations:

$$
\begin{aligned}
x_{t}^{h} & =\frac{X_{t}}{1+\frac{1-\alpha}{\alpha} S_{t}}, & x_{t}^{f} & =\frac{X_{t}}{1+\frac{\alpha}{1-\alpha} S_{t}} \\
y_{t}^{h} & =\frac{Y_{t}}{1+\frac{\alpha}{1-\alpha} S_{t}}, & y_{t}^{f} & =\frac{Y_{t}}{1+\frac{1-\alpha}{\alpha} S_{t}}
\end{aligned}
$$

where

$$
S_{t}=S_{t-1} \cdot \frac{M_{t}^{h}}{M_{t}^{f}}, \quad \forall t \geq 1
$$

and $S_{0}=\mu /(1-\mu)=1$ as we start the economy from an identical allocation of wealth. By comparing the set of equations (8) and (12), we can see that the allocations look very similar with one main difference: the share of world resources, $S_{t}$, is time-varying as determined by equation (13). In Appendix $\mathrm{C}$, we show that with complete markets consumption growth has an additional term compared to portfolio 
autarky:

$$
\Delta c_{t}^{i} \approx \Delta c_{t}^{i, a u t}+\lambda_{c}^{i} s_{t-1}+\lambda_{c c}^{i} s_{t-1}^{2}+\lambda_{s}^{i}\left(s_{t-1}\right) \xi_{t}, \quad i \in\{h, f\}
$$

where $s_{t} \equiv \log S_{t}, \lambda_{c}^{i}$ and $\lambda_{c c}^{i}$, are approximation parameters and $\lambda_{s}^{i}\left(s_{t-1}\right)$ is a timevarying function of the share of world consumption. This extra component changes the dynamics of consumption in at least three significant ways. First, it endogenously introduces an additional slowly moving predictive component of consumption growth, in addition to the two exogenous long-run risks. In section 5, we show that this endogenous component guarantees highly correlated pricing kernels even in the absence of international long-run risks.

Second, consumption responds immediately to news about future long-run growth prospects, as opposed to the basic Bansal and Yaron (2004) model, in which there is only a lagged response. In section 6.2, we show the predictions of our model for this response and in section 8 we document that US and UK data support our findings. Third, the component $S_{t}$ endogenously introduces a time-varying volatility term in consumption growth and helps us to explain the forward premium anomaly.

Prices. The price of the Arrow-Debreu securities expressed in terms of good $X$ in state $\xi_{t+1}$, is

$$
\begin{aligned}
Q_{t+1} & =M_{t+1}^{h} \cdot \frac{C_{x, t+1}^{h}}{C_{x, t}^{h}} \cdot f\left(\xi_{t+1}\right) \\
& =M_{t+1}^{f} \cdot \frac{C_{x, t+1}^{f}}{C_{x, t}^{f}} \cdot f\left(\xi_{t+1}\right),
\end{aligned}
$$

where $C_{x, t}^{i}=\partial C_{t}^{i} / \partial x_{t}^{i}, i \in\{h, f\}$. The terms of trade between good $X$ and $Y$ is

$$
p_{t}=\frac{\alpha+(1-\alpha) S_{t}}{(1-\alpha)+\alpha S_{t}} \cdot \frac{X_{t}}{Y_{t}}
$$

while the log growth of the real exchange rate is:

$$
\Delta e_{t}=\log M_{t}^{f}-\log M_{t}^{h} .
$$




\section{Equilibrium with complete markets: economic in- terpretation}

The equilibrium with portfolio autarky is straightforward and it does not require any further discussion. The complete markets' setup is instead non-standard because agents have recursive preferences. In particular, equations (12)-(16) suggest that in order to understand the dynamics of allocations and asset prices in this economy, we need to understand the dynamics of $S_{t}$.

What is $S_{t}$ ? $S_{t}$ indexes the relative share of world consumption at date $t$. Equivalently, when $S_{t}$ goes down, it means that the home country is decreasing its share of world consumption by exporting more and importing less. This means that $S_{t}$ can be thought as being proportional to Net Imports: when $S_{t}$ is high, the net value of imports is high; when $S_{t}$ is low, the net value of imports is low. Combining equations (12) and (15), it is possible to prove that:

$$
\frac{N I M P_{t}}{X_{t}}=-\frac{N X_{t}}{X_{t}}=\frac{(1-\alpha)\left(S_{t}-1\right)}{1-\alpha+\alpha S_{t}}
$$

where $N I M P_{t}$ and $N X_{t}$ denote Net Imports and Net Exports, respectively.

How does $S_{t}$ move? According to (13), $S_{t}$ drops when the home country receives good news to the stochastic supply of good $X$-the good that this country enjoys the most. This statement applies to both short- and long-run news. According to the economic interpretation that we offered above, therefore, we say that the home (foreign) country exports more when it fares better than the foreign (home) country in terms of endowment.

In figure 2 we depict the response of the log-ratio of the Pareto weights, $s_{t}=\log \left(S_{t}\right)$, to positive short- and long-run shocks to the supply of good $X{ }_{2}^{2}$ All parameters are calibrated to the values reported in table 1 for specification (1).

The bottom two panels of the figure show the counter-cyclical response of the ratio of the Pareto weights. Assuming that no shock affects the supply of the foreign good,

\footnotetext{
${ }^{2}$ We use a third order expansion of our system of equations (1)-(16) to characterize the equilibrium. We compute the policy function using the dynare++4.2.1 package. We notice no relevant difference when using a fourth order approximation. Mod file available upon request.
} 

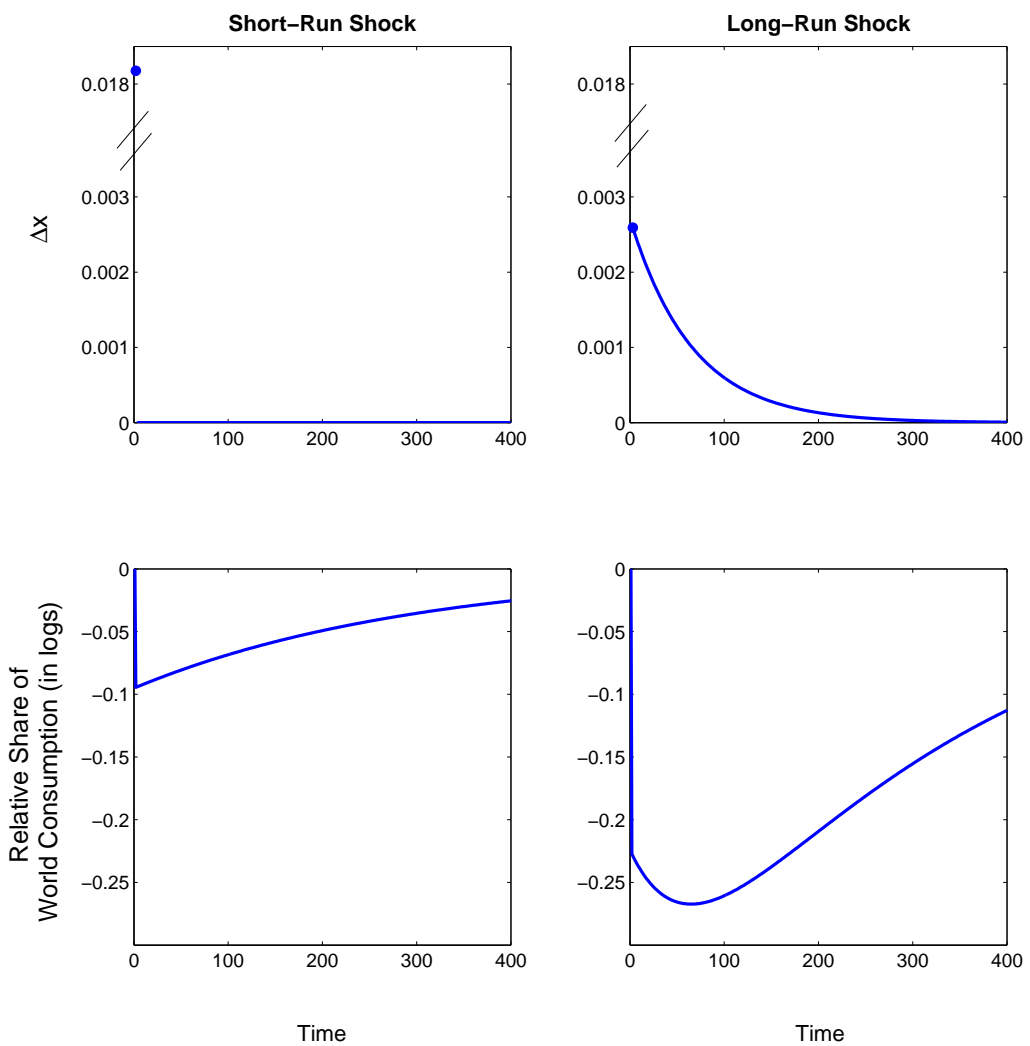

FIG. 2 - Ratio of Pareto Weights when IES = 1.5. This figure shows the impulse response function of the log-ratio of the Pareto weight, $s_{t}=\log \frac{\mu_{t}^{h}}{1-\mu_{t}^{h}}$. All parameters are calibrated to the values reported in Table 1 for specification (1). Shocks to the home country good endowment, $\Delta x$, materialize at time 1 .

good news to the supply of good $X$ imply a persistent reduction in the home Pareto weight and an increase of the foreign share of world consumption, consistent with our discussion of equation (13). By comparing the magnitude of the responses of $s_{t}$ across the two shocks, we see that even very small long-run shocks can produce a substantial and near permanent adjustment in the ratio of the Pareto weights, indeed promoting significant risk-sharing for the long-run.

Why does $S_{t}$ move? The dynamics of the model are driven by the tension between expected utility and utility variance that we have highlighted in equation (4): agents with recursive preferences are willing to trade-off higher expected future utility level, $E_{t}\left[U_{t+1}\right]$, for lower expected future utility risk, $\operatorname{Var}_{t}\left[U_{t+1}\right]$. We show this trade-off with 
and without long-run risk in figure 3 ,

The top-left panel shows the conditional expected utility of the home country as a function of the logarithm of the current ratio of the Pareto weight, $s_{t}$. The expected future utility is increasing in $s$, as a higher ratio of the Pareto weights corresponds to a higher share of world consumption. Adding a long-run risk to the economy reduces welfare and it explains why the dashed line (no long-run risk case) is lower than the solid line (model with long-run risk).

In the top-right panel, we depict the conditional variance of future utility as a function of $s_{t}$. The volatility is increasing in the ratio of the Pareto weights because a higher share of world consumption for the home country leaves smaller room for risksharing with the foreign partner and it implies higher exposure to aggregate risk. Not surprisingly, the model featuring both short- and long-run risk results in more utility-risk than the model without long-run risk (that is, the dashed line is above the thick line).

In the bottom-left panel, we plot the equilibrium conditional expectations and volatilities of the utility over the domain of the ratio of the Pareto weights. To facilitate their comparison, all frontiers have been re-centered at zero (we removed all intercepts) so that they can be easily plotted on the same scale. Two key results emerge from this picture. First, when a relative good shock to the home good materializes, the decline in the current share of home consumption produces a beneficial reduction in future utility risk that compensates the agent for the decline in future expected utility. Second, in a model with long-run risk, the trade-off frontier becomes steeper, implying that a more pronounced reduction in utility risk is required to compensate the agent for a given reduction of future expected utility level. Long-run risk, therefore, amplifies the risk-sharing motive of agents with recursive utilities.

In the bottom-right panel, we depict the conditional correlation of home and foreign continuation utilities-or, equivalently, life-time wealth—and point out two relevant results. First, even without long-run risk, life-time wealth tends to be highly correlated across countries. This is a natural result of our recursive risk-sharing scheme. 

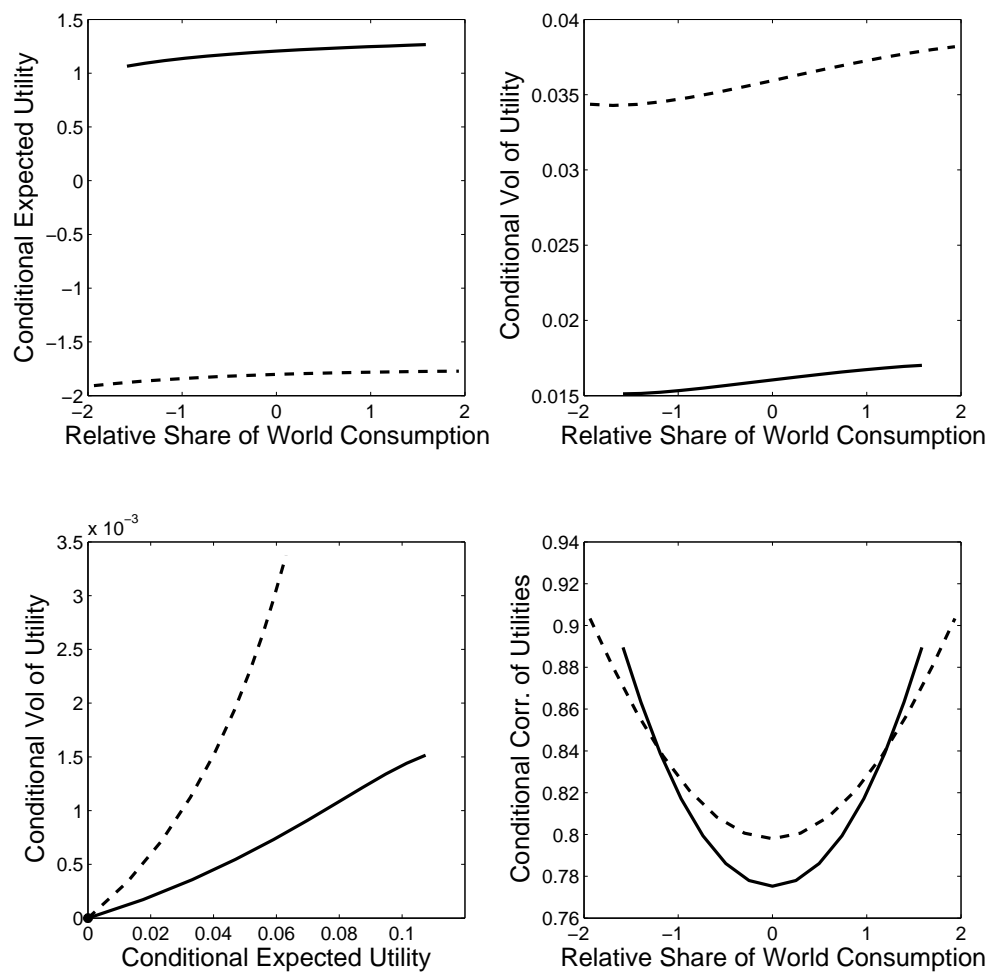

- - -With LRR —Without LRR

FIG. 3 - Utility mean-variance frontier and long-run risk. This figure shows the utility mean-variance frontier for the home country with and without long-run risks. By symmetry, a similar figure applies to the foreign country. The IES is set to 1.5, all other parameters are calibrated to the annual values reported in Table 1. All moments refer to the stationary process $U_{t+1}^{h} /\left(X_{t}^{\alpha} Y_{t}^{1-\alpha}\right)$. The relative share of World Consumption is measured by the log ratio of the Pareto weights, $s_{t}$.

As shown by the following optimality condition derived in $\mathrm{C}$,

$$
S_{t} \cdot \underbrace{\delta\left(\frac{C_{t+1}^{h}}{C_{t}^{h}}\right)^{-\frac{1}{\psi}}\left(\frac{U_{t+1}^{h 1-\gamma}}{E_{t}\left[U_{t+1}^{h 1-\gamma}\right]}\right)^{\frac{1 / \psi-\gamma}{1-\gamma}}}_{M_{t+1}^{h}} \cdot C_{x, t}^{h}=C_{x, t}^{f} \cdot \delta \underbrace{\delta\left(\frac{C_{t+1}^{f}}{C_{t}^{f}}\right)^{-\frac{1}{\psi}}\left(\frac{U_{t+1}^{f 1-\gamma}}{E_{t}\left[U_{t+1}^{f 1-\gamma}\right]}\right)^{\frac{1 / \psi-\gamma}{1-\gamma}}}_{M_{t+1}^{f}},
$$

continuation utilities are a natural device to equalize intertemporal marginal rates of substitution across countries and states of the world. Second, the conditional correlation of wealth across countries tends to increase with inequality, ie, as the relative 
share of world consumption tilts further in favor of one of our consumers. If we follow (?) in measuring risk-sharing by the correlation of the stochastic discount factors expressed in consumption bundle units, our model simply predicts that risk-sharing intensity is higher exactly when the agents need it the most, that is when one of them is close to consuming nothing for the rest of her life.

The role of IES. We highlight the role of the IES in figure 4. In the top-left panel, it is possible to see that a higher IES implies a lower unconditional expected utility. This is explained by the fact that as the elasticity gets larger, the agent is more affected by utility risk, hence her welfare declines.

Moreover, the top-right panel shows that the unconditional volatility of future utility declines, as the IES increases. This result is driven by a general equilibrium channel. As $\psi$ increases, a stronger risk-sharing incentive kicks in: agents become more and more adverse to utility risk and are more willing to give up part of their current consumption (through international trade) in exchange for smoother future utility profiles. A higher IES, therefore, reduces the amount of utility volatility that agents are willing to bear in equilibrium.

In the bottom-left panel, we show the utility mean-variance frontier for three different levels of the IES. Consistent with our intuition, as the IES increases the frontier becomes steeper, meaning that at the equilibrium a more substantial decline in wealth risk is required to offset drops in expected wealth due to an adjustment in the share of world endowments. The bottom-right panel shows that when the IES is high enough, the cross-country correlation of the stochastic discount factors is substantial as well, consistent with Colacito and Croce (2011). Moreover, the correlation of the stochastic discount factors is larger than the one of consumption growth rates over a large range of values for the IES.

\section{General Equilibrium Explanation of International Finance Anomalies}

In this section we focus on the implications of our model for the forward premium and the Backus and Smith (1993) anomalies, respectively. The forward premium anomaly 

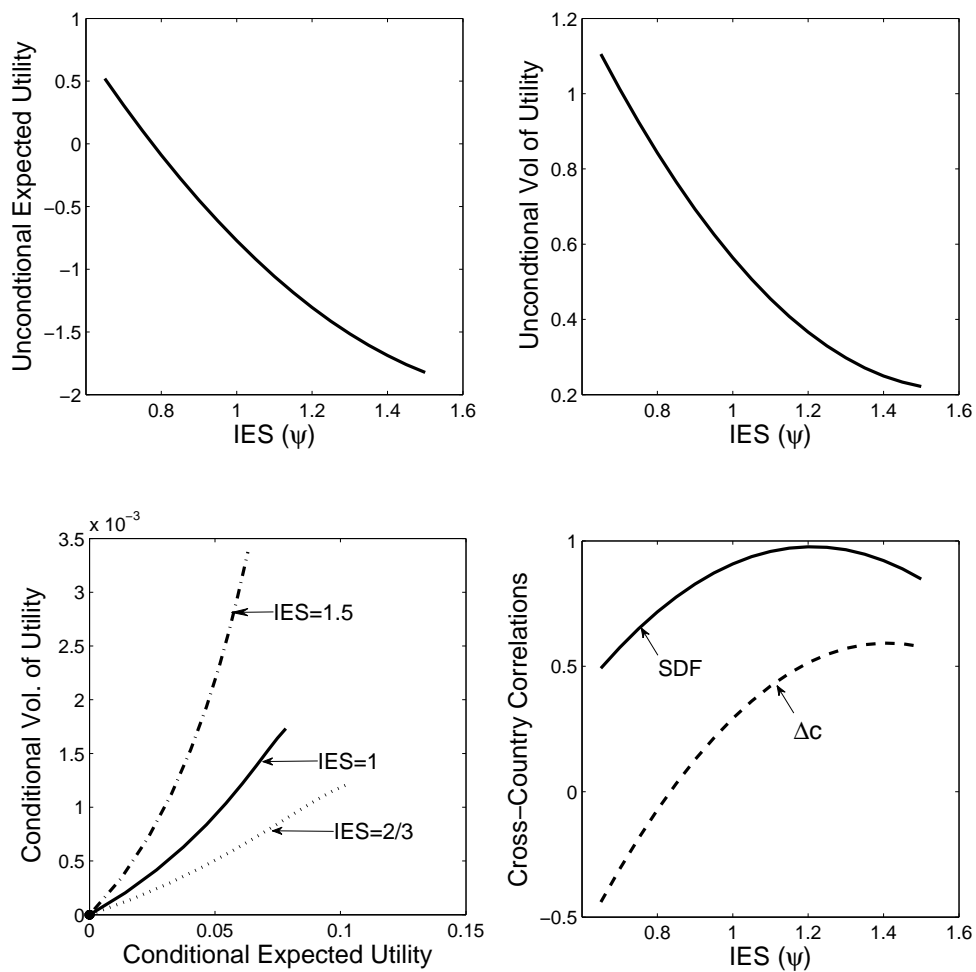

FIG. 4 - The utility mean-variance frontier for different levels of IES. This figure shows the utility mean-variance frontier for the home country across different levels of IES. All other parameters are calibrated to the values reported in Table1, By symmetry, a similar figure applies to the foreign country. The home country utility is standardized as follows: $U_{t+1}^{h} /\left(X_{t}^{\alpha} Y_{t}^{1-\alpha}\right)$. All other parameters are calibrated to the annual values reported in Table 1 .

refers to the empirical observation that high interest rate currencies tend to appreciate, contrary to what predicted by the uncovered interest rate parity relationship. Fama (1984) finds that time-varying volatility is a necessary condition to replicate this anomaly. Colacito (2008) and Bansal and Shaliastovich (2010) document that exogenous time-varying volatility can resolve the forward premium puzzle in a long-run risk setting. We show that the forward premium anomaly is actually an endogenous equilibrium outcome in a risk-sharing scheme with recursive preferences, a novel result in the literature. Furthermore, we show that this anomaly vanishes in a setting with limited capital mobility.

The Backus and Smith (1993) anomaly refers to the almost complete lack of corre- 
lation between consumption differentials across countries and exchange rates. Colacito and Croce (2011) have already shown that international long-run components paired with Epstein and Zin (1989) preferences can resolve this puzzle. Our study differs from previous analysis in at least two dimensions. First, our resolution of the Backus-Smith puzzle is based on a contemporaneous endogenous adjustment of consumption differentials upon the arrival of long-run news, a mechanism novel to the literature. Given its relevance, we also present new empirical evidence in favor of this channel. Second, we show that the transition from financial autarky to financial integration experienced by the US and the UK explains the structural change in the Backus-Smith correlation observed in the pre- and post-1970 data.

\subsection{The Forward Premium Anomaly}

Financial Autarky. We characterize the forward premium anomaly by looking at the OLS coefficient obtained by projecting the exchange rate growth onto the predetermined cross-country interest rate differential. We shall refer to this as the $\beta_{U I P}$. Given equations (8)-(10), in autarky the following holds:

$$
\begin{aligned}
E_{t}\left[\Delta e_{t+1}\right] & =\frac{1}{2 \alpha-1} E_{t}\left[\Delta c_{t+1}^{h}-\Delta c_{t+1}^{h}\right] \\
& =\frac{\psi}{2 \alpha-1}\left(r_{t}^{h}-r_{t}^{f}\right),
\end{aligned}
$$

which implies $\beta_{U I P}^{\text {aut }}=\psi /(2 \alpha-1)>0$. In financial autarky, therefore, obtaining a positive $\beta_{U I P}$ should not come as a surprise. If we think of the pre-1970 sample as a period of limited capital mobility, financial autarky rationalizes the positive $\beta_{U I P}$ that we find in the data.

International Complete Markets. Assume that $\widetilde{U}_{t}^{h} \equiv U_{t}^{h} /\left(X_{t}^{\alpha} Y_{t}^{1-\alpha}\right)$ and $\widetilde{U}_{t}^{f} \equiv$ $U_{t}^{f} /\left(X_{t}^{1-\alpha} Y_{t}^{\alpha}\right)$ are approximately log-normally distributed. Under our symmetric cal- 
ibration we show in Appendix $\mathrm{D}$ that the difference of the risk-free rates is:

$$
\begin{aligned}
r_{t}^{h}-r_{t}^{f} \approx & \frac{1}{\psi}\left(E_{t}\left[\Delta c_{t+1}^{h}\right]-E_{t}\left[\Delta c_{t+1}^{f}\right]\right) \\
& -\frac{1}{2}\left(\frac{1}{\psi}\right)^{2} \cdot\left(V_{t}\left[\Delta c_{t+1}^{h}\right]-V_{t}\left[\Delta c_{t+1}^{f}\right]\right) \\
& +\frac{1}{2} \underbrace{\left(1-\frac{1}{\psi}\right)\left(\frac{1}{\psi}-\gamma\right)}_{<0, \text { if } \psi>1 \text { and } \psi>1 / \gamma}\left(V_{t}\left[\log \widetilde{U}_{t+1}^{h}\right]-V_{t}\left[\log \widetilde{U}_{t+1}^{f}\right]\right) .
\end{aligned}
$$

It is also possible to show that the expected growth of the real exchange rate takes the following form:

$$
\begin{aligned}
E_{t}\left[\Delta e_{t+1}\right] \approx & \frac{1}{\psi}\left(E_{t}\left[\Delta c_{t+1}^{h}\right]-E_{t}\left[\Delta c_{t+1}^{f}\right]\right) \\
& +\frac{1}{2} \underbrace{(1 / \psi-\gamma)(1-\gamma)}_{>0, \text { if } \psi>1 / \gamma \text { and } \gamma>1} \cdot\left(V_{t}\left[\log \widetilde{U}_{t+1}^{h}\right]-V_{t}\left[\log \widetilde{U}_{t+1}^{f}\right]\right)
\end{aligned}
$$

Both expected exchange rate growth and interest rate differential depend on first and second moments of consumption growth rates and continuation utilities. Expected consumption growth differentials tend to produce a positive co-movement between $E_{t}\left[\Delta e_{t+1}\right]$ and $r_{t}^{h}-r_{t}^{f}$ as in the case of standard CRRA preferences. Without the endogenous time-varying second moments that arise in equilibrium, all other terms would be constant and the $\beta_{U I P}$ would be exactly one. In what follows, we explain how endogenous time-varying risk helps us getting a low $\beta_{U I P}$, provided that $\psi>1$ and $\psi>1 / \gamma$.

Consider the case of a positive shock to the growth rate of good $X$. As this happens, the home country risk-free rate increases for three reasons: (i) it is expected to consume relatively more in the future (higher $E_{t}\left[\Delta c_{t+1}^{h}\right]$ ); (ii) it achieves a smoother future consumption profile by trading away part of its current consumption (lower $V_{t}\left[\Delta c_{t+1}^{h}\right]$ ), and (iii) it locks is a less risky wealth profile (lower $V_{t}\left[\log \widetilde{U}_{t+1}^{h}\right]$ ).

Turning our attention to the real exchange rate, we notice that two forces are at work in opposite directions. On the one hand, the home currency is expected to depreciate as a consequence of the larger supply of the home good (higher $E_{t}\left[\Delta c_{t+1}^{h}\right]$ ). On the other hand, there is also an appreciation pressure thorugh the utility-risk channel. 
Upon the realization of relative good news to $X$, the home country locks in a safer utility profile (lower $V_{t}\left[\Delta c_{t+1}^{h}\right]$ ), implying that its entire future consumption stream is less risky. By no arbitrage, the domestic consumption bundle is more valuable than the foreign one and the exchange rate should appreciate. Depending on which effect dominates, the home currency will either appreciate or depreciate.

The role of the IES. The forward premium anomaly effectively puts both a lower and an upper bound on the IES. Indeed, a calibration with a large enough $\psi$ is needed to have a quantitatively relevant utility mean-variance trade-off (see figure 4). However, this preference parameter cannot be too large, as an increasing level of IES produces an overall reduction in the amount of volatility in the model (see figure 4) and it reduces the contribution of the time-varying second moments in (18)-(19). In section 7.1, we quantify the intensity of these different forces by looking at simulated moments from the model and suggest 1.5 as benchmark value for the IES.

\subsection{The Backus and Smith Puzzle}

Financial Autarky. Combining equations $(8)$ and (10), it follows immediately that:

$$
\Delta c_{t}^{h, a u t}-\Delta c_{t}^{f, a u t}=(2 \alpha-1)\left(\Delta x_{t}-\Delta y_{t}\right)=\Delta e_{t} .
$$

Hence, under financial autarky the correlation between consumption differentials and exchange rate is 1 , a value that goes in the direction of our empirical findings for the pre-1970 sample.

Internationally Complete Markets. Under complete markets, we do not have closed form solutions for the dynamics of consumption. In order to inspect the implications of our model for the Backus and Smith correlation, we analyze the impulse response functions depicted in figure 5. We proceed in two steps. First, we consider the case of a positive short-run shock to the supply of good $X$ (the most preferred good for the home country). Then, we focus on the case of a positive long-run shock to the supply of the same good.

Following a positive short-run shock, the home country exports part of its abundant supply of good $X$, but because of home bias there is only a limited amount of good $X$ that the foreign country is willing to take. This means that consumption will increase 
in both countries, but relatively more at home (see the third panel on the left column of figure 5). Since good $X$ is more abundant, the marginal utility of consumption is lower at home than in the foreign country. This leads to a depreciation of the home currency. So, following a short-run shock, there is a positive co-movement between consumption differentials and exchange rate.

Upon the realization of a long-run shock, the situation is quite different (see right columns of figure 5). By looking at the scale in the $\Delta x$ panel, we notice that on impact this shock is a factor of magnitude smaller than a short-run shock. However, by its very definition, this shock is going to affect the growth rate of good $X$ for a very long time. The lifetime utility value of this type of shock is extremely large. The home country rejoices, to the point that it takes a reduction of its current consumption to restore the equality of the marginal rates of substitutions. While home consumption drops, foreign consumption increases thanks to higher net imports. The implied consumption growth differential declines and becomes negative. Also in this case, the home currency depreciates given the expectation of a relatively larger supply of the home good in periods to come. The net effect is a negative correlation between consumption differentials and exchange rate's fluctuations.

By combining the left and the right panels of figure 5, we can conclude that on average we are going to get $\operatorname{corr}\left(\Delta e_{t}, \Delta c_{t}^{H}-\Delta c_{t}^{f}\right)<1$, a necessary condition to replicate the Backus-Smith anomaly in the post-1970 sample. The final quantitative impact of long-run shocks depend on the calibration of the IES. As for the forward premium anomaly, we point out that a large IES can reduce the ability of the model to explain the Backus-Smith puzzle. To explain this point, we depict the impulse response function of several home country variables for different levels of IES in figure 6. The left panels show that changing the IES does not significantly alter the behavior of our model with respect to short-run shocks.

Turning our attention to the right panels, instead, we see that the impact of long-run shocks strongly depends on the chosen level of the IES. Specifically, as the elasticity gets larger, the adjustment of the stochastic discount factor is smaller. This is due to the two competing forces affecting the stochastic discount factor: the immediate drop in consumption tends to increase the pricing kernel, while the higher continuation utility tends to decrease it. When the IES is set to 1.8, these two effects perfectly cancel out with each other. By no arbitrage, the moderation in the adjustment of 

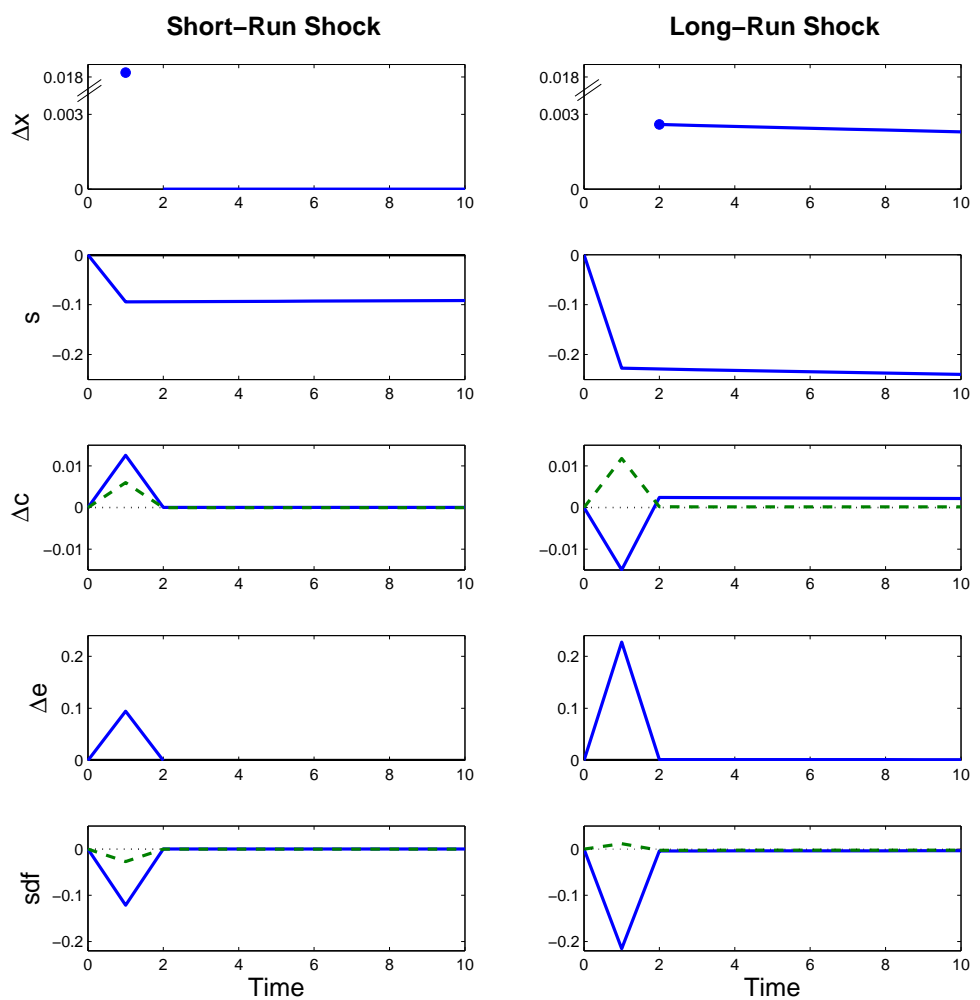

-Home - - -Foreign

FIG. 5 - Impulse Response Functions when IES = 1.5. This figure shows the impulse response function of several variables of interest for both the home (solid line) and the foreign country (dashed line). All parameters are calibrated to the values reported in Table 1 and the IES is set to 1.5 . Shocks materialize at time 1 .

the home country stochastic discount factor implies a reduction in the change of the exchange rate. As the IES gets larger and larger, the negative co-movement between consumption differential and exchange rate growth becomes less important and their unconditional correlation is back being close to one. 

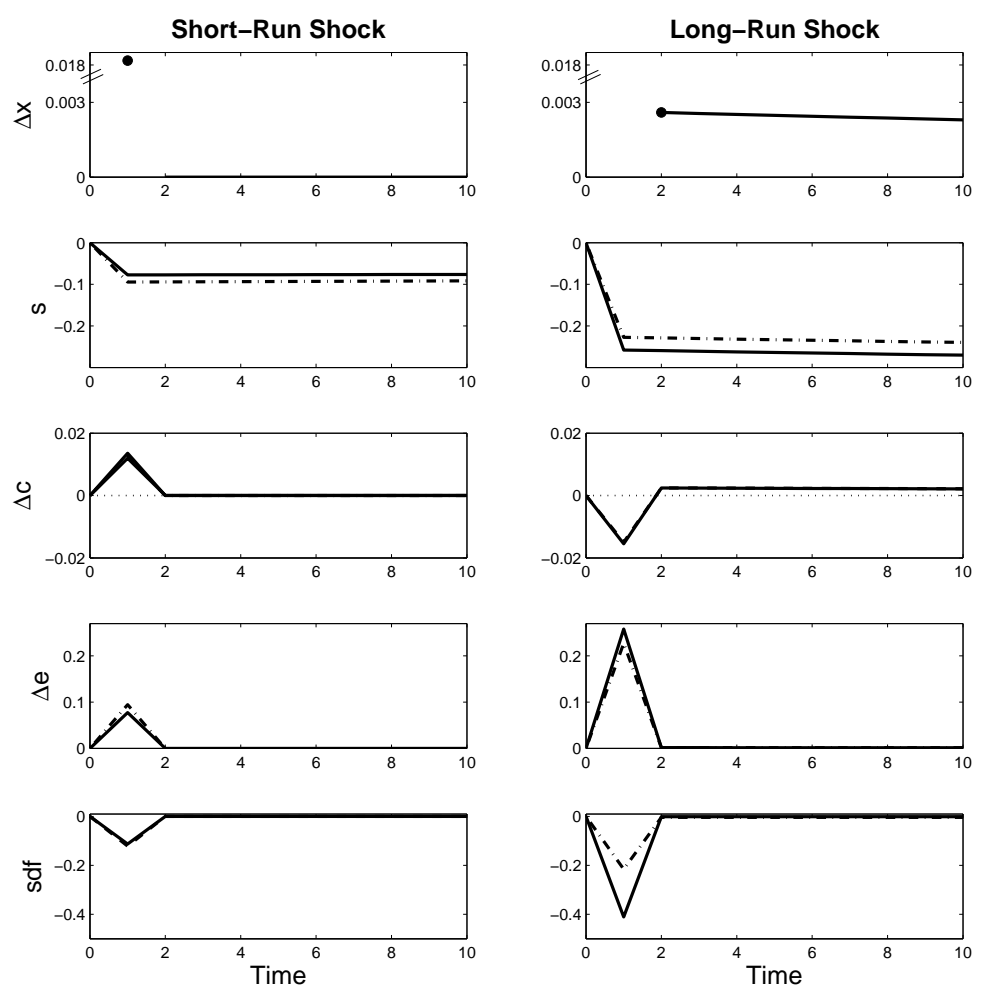

IES $=0.67--\operatorname{IES}=1.5$

FIG. 6 - Impulse Response Functions for different levels of IES. This figure shows the impulse response function of several variables of interest for the home country across different levels of IES. The dot-dashed line depicts the impulse responses when IES = 1.5; the thick line is obtained setting IES $=0.67$. All other parameters are calibrated to the values reported in Table1, Shocks materialize at time 1.

\section{Simulated Moments}

\subsection{Complete Markets}

In table 1 we report moments from both our model and our dataset. Specification (1) is our preferred calibration as it features an IES consistent with Bansal and Yaron (2004), and it features both short- and long-run risks. In specification (2) we remove long-run risks to better asses their contribution in the context of our model. Specifications (3) and (4) show how the performance of the model changes when the IES drops. All other parameters are calibrated as in Colacito and Croce (2010b). 
TABLE 1

Results with Complete Markets

\begin{tabular}{|c|c|c|c|c|c|}
\hline \multicolumn{6}{|c|}{ Panel A: calibration of common parameters. } \\
\hline$\mu$ & $\sigma_{x}$ & $\rho$ & $\rho_{12} \quad \rho_{x y}$ & $\alpha$ & $\gamma$ \\
\hline $2.00 \%$ & $4 \% \sigma$ & .985 & .90 & .97 & 8 \\
\hline \multicolumn{6}{|c|}{ Panel B: main moments. } \\
\hline Specification & DATA & (1) & $(2)$ & (3) & (4) \\
\hline \multirow[t]{2}{*}{$\operatorname{IES}(\psi)$} & & 1.5 & 1.5 & 1 & $2 / 3$ \\
\hline & & (with LRR) & (no LRR) & \multicolumn{2}{|c|}{ (with LRR) } \\
\hline \multirow{3}{*}{$\begin{array}{l}\operatorname{Std}(\Delta c) / \operatorname{Std}(\Delta y) \\
\operatorname{ACF}_{1}\left(\Delta c_{t}\right) \\
\operatorname{corr}\left(\Delta c_{t}^{h}, \Delta c_{t}^{f}\right)\end{array}$} & 0.87 & 0.99 & 0.88 & 1.07 & 1.37 \\
\hline & 0.38 & 0.37 & 0.01 & 0.33 & 0.27 \\
\hline & 0.55 & 0.59 & 0.90 & 0.35 & -0.40 \\
\hline $\mathrm{E}\left[r_{f}\right]$ & 1.25 & 1.82 & 2.93 & 3.22 & 4.94 \\
\hline $\operatorname{Std}\left[r_{f}\right]$ & 1.15 & 0.87 & 0.03 & 1.46 & 2.08 \\
\hline $\operatorname{corr}\left(r_{f, t}^{h}, r_{f, t}^{f}\right)$ & 0.64 & 0.89 & -1.00 & 0.94 & 0.90 \\
\hline $\operatorname{Std}[\mathrm{M}] / \mathrm{E}[\mathrm{M}]$ & & 28.11 & 13.27 & 69.51 & 91.47 \\
\hline \multirow{3}{*}{$\begin{array}{l}\operatorname{Std}\left(\Delta e_{t}\right) \\
\operatorname{corr}\left(\Delta c_{t}^{h}-\Delta c_{t}^{f}, \Delta e_{t}\right) \\
\beta_{U I P}\end{array}$} & 11.65 & 15.17 & 6.67 & 20.73 & 67.19 \\
\hline & -0.02 & 0.12 & 1.00 & -0.23 & -0.04 \\
\hline & -0.72 & -1.15 & -43.23 & -2.28 & -0.60 \\
\hline
\end{tabular}

Notes - In Panel A we report our annual calibration employed for the post-Bretton-Wood sample (1970-2006). The data sources are explained in detailed in section A. The IES is allowed to vary across different model specifications. For specification (2), we impose $\sigma_{x}=0$ and $\rho_{x y}=0.35$ so that the cross-country correlation of the output growth rates is kept constant across all calibrations.

Benchmark Calibration. Specification (1) perfectly reproduces the cross-country correlation and the autocorrelation of consumption growth rates observed in the post1970 sample. Since our model cannot fully match the volatility of the bilateral net export ratio between US and UK, short-run consumption growth rates are only slightly smoother than endowment growth rates.

On the asset pricing side, our model performs well along several dimensions. We can replicate the average level and volatility of the risk-free rates. The stochastic discount factor is volatile and matches the Hansen and Jagannathan (1991) bound. Despite the high volatility of the pricing kernels, the growth rate of the exchange 
rate is smooth as in Colacito and Croce (2011) thanks to the high correlation of the long-run components. The cross-country correlation of the risk-free rate, however, is higher than that observed in the data because of the high cross-country correlation of the long-run components.

The model successfully replicates the almost lack of correlation between exchange rate and consumption growth differential, consistent with Backus and Smith (1993)'s findings. Additionally, the predicted $\beta_{U I P}$ is negative and close in value to its empirical counterpart.

The role of long-run risk. In specification (2) we shut down international longrun risks and let output growth be driven only by short-run fluctuations. The model fails along several dimensions. The contemporaneous correlation between home and foreign consumption is almost one, in contrast to the data. This is a reflection of the fact that home and foreign consumption adjust in the same direction upon the realization of short-run supply shocks.

The risk-free rates are driven only by the relative share of wealth, $s_{t}$, that has now little volatility and negative cross-country correlation (mechanically, when the home share of consumption increases the foreign one decreases). Hence, risk-free rates are excessively smooth and perfectly negatively correlated, which is at odds with the empirical evidence.

Exchange rate and pricing kernels are not volatile enough. In particular, it is important to notice that upon removing long-run risks, the market price of risk declines by more than $50 \%$, implying that international long-run risk may explain a significant share of the dynamics of international asset prices.

The model without long-run risks cannot reproduce the Backus-Smith correlation as the the exchange rate is just a reflection of short-run consumption dynamics, consistent with our analysis of the impulse response functions. Furthermore, the model 
produces an excessively negative UIP regression coefficient, a consequence of the interest rate differential becoming much smoother and actually almost constant.

The role of the IES. Specifications (3) and (4) show the performance of the model with both short- and long-run risk for an IES equal to 1 and 0.67 , respectively. We highlight four points. First, with a lower IES agents are willing to accept more risk hence their stochastic discount factors become much more volatile. Second, given the higher volatility of the pricing kernels, the exchange rate variance increases as well reaching counterfactual high levels. Third, according to equations (18)-(19), when the IES is smaller than 1, time-varying volatility tends to increase the value of the $\beta_{U I P}$ coefficient. Fourth, the risk-free rate tends to become too high on average and too volatile as the IES declines. The risk-free rate puzzle, the forward premium anomaly and the Backus-Smith puzzle, therefore, jointly put a lower bound on the IES suggesting that it should be calibrated to a value at least as high as 1 .

\subsection{Results across capital mobility regimes}

When looking at the pre-1970 data, we alter our benchmark calibration by decreasing the international correlations of short- and long-run shocks to better match international correlations of endowments.

After refining the calibration, our model with financial autarky is able to replicate several key features of the data. First, table 2 documents that the cross-country correlation of the consumption growth rates is close to zero due to the lack of intertemporal risk-sharing, consistent with the pre-1970 data.

Furthermore, consumption growth adjusts almost one-to-one with the growth of the home endowment, because of consumption home bias (see equation (8)). The extent of exchange rate's fluctuations is moderate, since in both countries the endowment 
TABLE 2

RESUlts WiTh AUTARKY

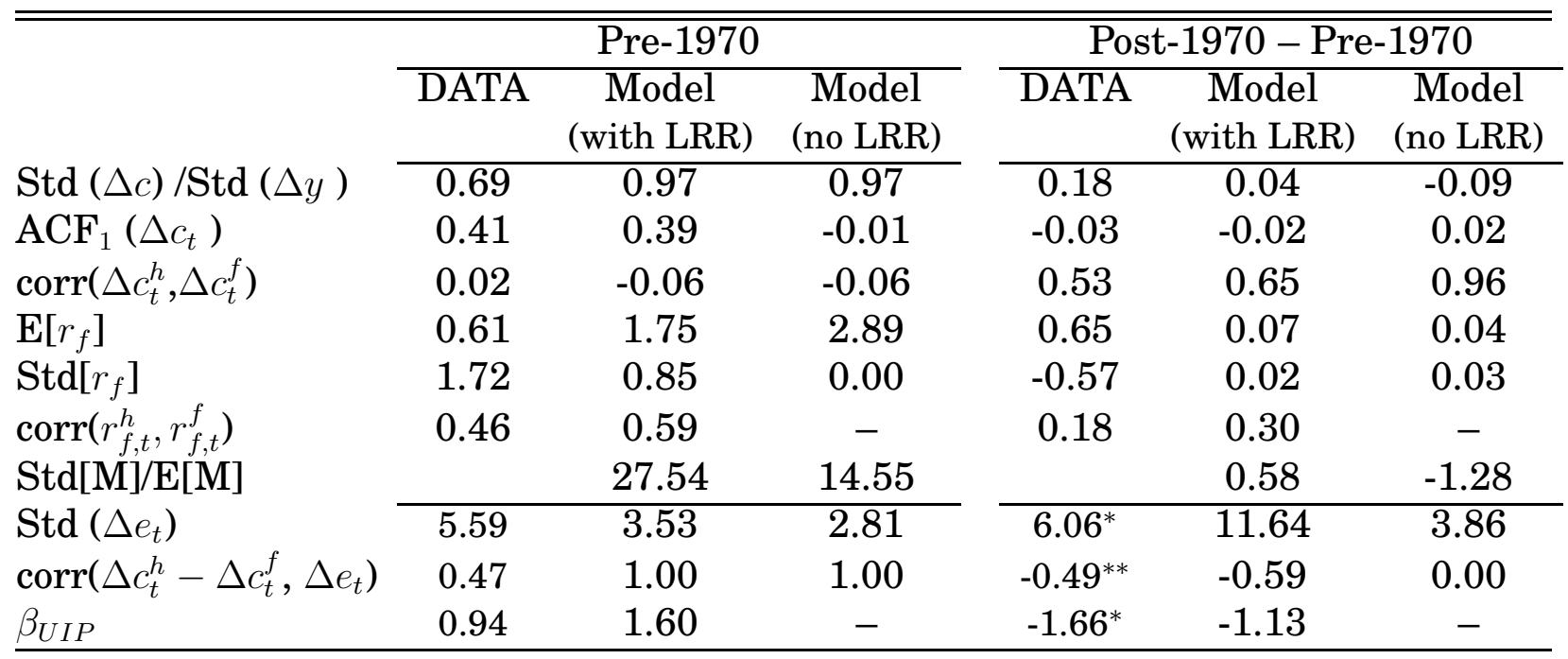

Notes - We adopt the calibration corresponding to specification (1) in table 1 and adapt it to the pre-1970 sample as follows: (1) in the model with long-run risk, we set $\rho_{12}=0.50$ and $\rho_{12}=-0.50 ;(2)$ in the model without long-run risk we set $\rho_{x y}=-0.12$. This enables us to match the lower correlation of the long-run components in the pre-1970 sample and keep the unconditional correlation of output growth constant across model specifications. The data sources are explained in detailed in section $\mathrm{A}$. The last three columns refer to the change in the moments of interest across the post-1970 and pre-1970 sample for the data, and across the model with internationally complete markets and financial autarky. We test the null of no change in $\operatorname{Std}\left(\Delta e_{t}\right), \operatorname{corr}\left(\Delta c_{t}^{h}-\Delta c_{t}^{f}, \Delta e_{t}\right)$, and $\beta_{U I P}$ across regimes and denote $p$-values smaller than $1 \%$ and $2 \%$ by $^{*}$ and ${ }^{* *}$, respectively.

growth rate has a low volatility, again consistent with empirical evidence. Longrun shocks no longer generate lack of co-movement between exchange rate and the difference of consumption growth rates, since the share of world consumption is constrained to be constant. This implies that $\operatorname{corr}\left(\Delta c_{t}^{h}-\Delta c_{t}^{f}, \Delta e_{t}\right)$ increases by an amount comparable to that observed in our sub-samples. Additionally, the lack of timevarying volatility brings the the UIP regression coefficient closer to the one that we observe in the data.

Risk-free rates are less correlated than in the post-1970 sample, because of the lower measured correlation of the long-run components. Overall, the model with long-run 
risk reproduces quite accurately the changes occurred in the pre- and post-1970 periods.

The role of long-run risk in the pre-1970 sample. As shown in the last column of table 2, the model without long-run risk misses several key aspects of the transition occurred in the seventies. First of all, the model cannot replicate the higher volatility of the exchange rate in the post-1970 and the lower correlation between short-run consumption growth differentials and exchange rate movements. Furthermore, consumption growth is i.i.d. in both countries and risk-free rates are constant, implying that there is no scope for predictability of exchange rate growth.

\section{Empirical Evidence on Consumption Behavior}

Our model accounts for the behavior of international prices and quantities in the post-1970 sample thanks to its specific predictions about the response of consumption growth to short- and long-run news. Focusing on the financial integration regime, we discussed how consumption growth differentials (defined as $\Delta c_{t}^{h}-\Delta c_{t}^{f}$ ) should evolve as follows:

$$
\Delta c_{t}^{h}-\Delta c_{t}^{f}=f(\underbrace{\varepsilon_{x, t}}_{+}, \underbrace{\varepsilon_{y, t}}_{-}, \underbrace{\varepsilon_{1, t}}_{-}, \underbrace{\varepsilon_{2, t}}_{+}) .
$$

That is, consumption differentials should increase (decline) upon the realization of positive (negative) home short-run news and foreign long-run news. In this section we test these predictions in order to provide further empirical support to our model.

We follow Colacito and Croce (2011), and Bansal, Kiku and Yaron (2010) to identify short- and long-run innovations to GDP growth by the means of predictive regressions. We regress GDP growth in the US and in the UK on a set of predictive variables 
denoted by $F^{U S}$ and $F^{U K}$ :

$$
\begin{aligned}
\Delta G D P_{t+1}^{U S} & =: \Delta x_{t+1}=\beta^{U S} F_{t}^{U S}+\varepsilon_{x, t+1} \\
\Delta G D P_{t+1}^{U K} & =: \Delta y_{t+1}=\beta^{U K} F_{t}^{U K}+\varepsilon_{y, t+1} .
\end{aligned}
$$

We form $F_{t}^{U S}$ and $F_{t}^{U K}$ using four different sets of variables commonly used in the long-run risk literature to identify long-run components:

$$
\begin{aligned}
F_{1, t}^{i} & =\left[p d_{t}^{i}\right] \\
F_{2, t}^{i} & =\left[p d_{t}^{i}, r f_{t}^{i}\right] \\
F_{3, t}^{i} & =\left[p d_{t}^{i}, c y_{t}^{i}, \Delta G D P_{t}^{i}\right] \\
F_{3, t}^{i} & =\left[p d_{t}^{i}, c y_{t}^{i}, \Delta G D P_{t}^{i}, r f_{t}^{i}, \text { default }_{t}^{i}\right], \quad \forall i \in\{U S, U K\}
\end{aligned}
$$

where $p d, r f, c y$, and default denote the price-dividend ratio, the risk-free rate, the consumption output ratio, and the default spread, respectively. We then use the projections of GDP growth on these sets of variables as our measure of long-run risks:

$$
\widehat{z}_{1, j, t}=\widehat{\beta}_{j}^{U S} F_{j, t}^{U S}, \quad \text { and } \quad \widehat{z}_{2, j, t}=\widehat{\beta_{j}^{U K}} F_{j, t}^{U K}
$$

and identify long-run news as the innovations in the following regressions

$$
\begin{aligned}
& \widehat{z}_{1, j, t}=\rho_{1} \widehat{z}_{1, j, t-1}+\varepsilon_{1, j, t} \\
& \widehat{z}_{2, j, t}=\rho_{2} \widehat{z}_{2, j, t-1}+\varepsilon_{2, j, t}, \quad \forall j=\{1,2,3,4\} .
\end{aligned}
$$

We report the results of our estimations in table 3 . We are interested in the sign of the response of consumption growth differentials to both short- and long-run innovations to GDP growth. The results are consistent with our theory, meaning that all sharply identified coefficients have a sign consistent with that suggested by our model. In 
TABLE 3

CONSUMPTION GROWTH DIFFERENTIALS AND SHORT- AND LONG-RUN SHOCKS

\begin{tabular}{lcccc}
\hline \hline & pd only & pd and rf & pd,cy,dy & pd,cy,dy,rf,def \\
\hline$\varepsilon_{x, t}$ & $0.005^{* * *}$ & $0.006^{* * *}$ & $0.013^{* * *}$ & $0.005^{* * *}$ \\
& {$[4.40]$} & {$[4.77]$} & {$[4.79]$} & {$[3.83]$} \\
$\varepsilon_{1, t}$ & -0.013 & 0.002 & $-0.020^{* * *}$ & -0.003 \\
& {$[-1.50]$} & {$[0.90]$} & {$[-3.29]$} & {$[-1.31]$} \\
$\varepsilon_{y, t}$ & $-0.010^{* * *}$ & $-0.008^{* * *}$ & $-0.008^{* * *}$ & $-0.011^{* * *}$ \\
& {$[-10.58]$} & {$[-9.38]$} & {$[-11.60]$} & {$[-7.72]$} \\
$\varepsilon_{2, t}$ & 0.003 & -0.003 & $0.008^{* *}$ & $0.005^{*}$ \\
& {$[1.00]$} & {$[-1.23]$} & {$[2.37]$} & {$[1.87]$} \\
\hline
\end{tabular}

Notes - The table reports the estimated coefficients of the regressions of $\Delta c_{t}^{h}-\Delta c_{t}^{f}$ on the four short- and long-run shocks. All regressions include a constant and the estimated predictive components as controls. The numbers in brackets correspond to t-stats. We use ${ }^{* * *}{ }^{* *}$ and ${ }^{*}$ to denote $p$-values smaller than $1 \%, 5 \%$ and $10 \%$, respectively.

particular, the best results are obtained with the last two specifications (columns 3 and 4) in which both asset prices and quantities are used to filter the low frequency components of GDP growth. All the estimated coefficients in these last two specifications have the sign predicted by the model and, except for one case, they are all statistically significant at conventional levels. We regard this result as significantly in favor of our recursive risk-sharing mechanism.

\section{Concluding remarks}

In this paper we have developed an international recursive general equilibrium model with long-run risk that is able to account for a number of quantitatively challenging facts of international finance. More precisely, the model generated series that agree with both international prices and quantities across different capital mobility regimes, a finding new to the international finance literature. Given the potential of the model and the relatively simple solution technique adopted in this study, we believe that it could easily be extended to international real business cycles settings in order to study international investment flows, portfolio diversification, and diffusion 
of real regional shocks across countries and currencies. 


\section{Appendix}

\section{A: Data Sources}

Data on US consumption of nondurables and services, gross domestic product, and population were collected from the NIPA tables of the Bureau of Economic Analysis. Value-weighted market returns, yields on 3-month T-bills, dividends, and dividend yields for the US are from CRSP. CPI inflation and total imports and exports were obtained from the website of the Federal Reserve of St. Louis. The UK consumption series for the years 1963-2006 were obtained from the UK Office of National Accounts. For earlier data, we referred to Mitchell (2007). Bilateral imports and exports are also reported in Mitchell (2007). Long time series for the UK gross domestic product, FTSE returns, yields on three-month T-bills, dividend yields, population, and CPI inflation were obtained from the website of Global Financial Data.

\section{B: Mean-Variance Approximation of the Utility Function}

Epstein and Zin preferences are defined as

$$
U_{t}=\left\{(1-\delta) C_{t}^{(1-\gamma) / \rho}+\delta E_{t}\left[U_{t+1}^{1-\gamma}\right]^{1 / \rho}\right\}^{\rho /(1-\gamma)}
$$

where $\rho=(1-\gamma) /(1-1 / \psi)$. Define $V_{t}=U_{t}^{1-1 / \psi} /(1-1 / \psi)$. It follows that

$$
V_{t}=(1-\delta) \frac{C_{t}^{(1-\gamma) / \rho}}{1-1 / \psi}+\delta E_{t}\left[V_{t+1}^{\rho}\right]^{1 / \rho}
$$

Taking a second order Taylor expansion of $V_{t+1}^{\rho}$ about $E_{t}\left[V_{t+1}\right]$ yields

$$
V_{t+1}^{\rho} \approx E_{t}\left[V_{t+1}\right]^{\rho}+\rho E_{t}\left[V_{t+1}\right]^{\rho-1}\left(V_{t+1}-E_{t}\left[V_{t+1}\right]\right)-\frac{\rho(1-\rho)}{2} E_{t}\left[V_{t+1}\right]^{\rho-2}\left(V_{t+1}-E_{t}\left[V_{t+1}\right]\right)^{2}
$$


Taking a first order Taylor expansion of $E_{t}\left[V_{t+1}^{\rho}\right]^{1 / \rho}$ using the above approximation for $V_{t+1}^{\rho}$ and evaluating it at $\rho=1$ delivers

$$
V_{t} \approx \frac{C_{t}^{1-1 / \psi}}{1-1 / \psi}+\delta E_{t}\left[V_{t+1}\right]+\frac{\delta}{2} \frac{\rho-1}{E_{t}\left[V_{t+1}\right]} \operatorname{Var}_{t}\left[V_{t+1}\right]
$$

In the body of the paper, we report this approximation by defining $\theta=-(\rho-1)$.

\section{C: Allocation as a Function of Pareto-weights}

TBC

\section{D: Approximation of risk-free rates and expected exchange rate growth}

Define $\widetilde{U}_{t}^{h} \equiv U_{t}^{h} /\left(X_{t}^{\alpha} Y_{t}^{1-\alpha}\right)$ and $\widetilde{U}_{t}^{f} \equiv U_{t}^{f} /\left(X_{t}^{1-\alpha} Y_{t}^{\alpha}\right)$. The log-stochastic discount factors are:

$$
m_{t+1}^{i}=\log (\delta)-\frac{1}{\psi} \Delta c_{t+1}^{i}+\left(\frac{1}{\psi}-\gamma\right) \log \widetilde{U}_{t}^{i}-\frac{1 / \psi-\gamma}{1-\gamma} \log E_{t}\left[\exp \left\{(1-\gamma) \log \widetilde{U}_{t}^{i}\right\}\right]
$$

$\forall i \in\{h, f\}$. If we assume that $\widetilde{U}_{t}^{h}$ and $\widetilde{U}_{t}^{f}$ are approximately log-normally distributed, then the stochastic discount factors can be approximated as:

$$
\begin{aligned}
m_{t+1}^{i}= & \log (\delta)-\frac{1}{\psi} \Delta c_{t+1}^{i}+\left(\frac{1}{\psi}-\gamma\right) \log \widetilde{U}_{t}^{i}-(1 / \psi-\gamma) E_{t}\left[\log \widetilde{U}_{t}^{i}\right] \\
& -\frac{1}{2}(1-\gamma)\left(\frac{1}{\psi}-\gamma\right) V_{t}\left[\log \widetilde{U}_{t}^{i}\right], \quad \forall i \in\{h, f\}
\end{aligned}
$$


Then, under a symmetric calibration, the difference of the risk-free rates is:

$$
\begin{aligned}
r_{t}^{h}-r_{t}^{f}= & -\log E_{t}\left[\exp \left\{m_{t+1}^{h}\right\}\right]+\log E_{t}\left[\exp \left\{m_{t+1}^{f}\right\}\right] \\
= & \frac{1}{\psi}\left(E_{t}\left[\Delta c_{t+1}^{h}\right]-E_{t}\left[\Delta c_{t+1}^{f}\right]\right)-\frac{1}{2}\left(\frac{1}{\psi}\right)^{2} \cdot\left(V_{t}\left[\Delta c_{t+1}^{h}\right]-V_{t}\left[\Delta c_{t+1}^{f}\right]\right) \\
& +\left(\frac{1}{\psi}-\gamma\right)\left(\operatorname{Cov}_{t}\left[\Delta c_{t+1}^{h}, \log \widetilde{U}_{t+1}^{h}\right]-\operatorname{Cov}_{t}\left[\Delta c_{t+1}^{f}, \log \widetilde{U}_{t+1}^{f}\right]\right) \\
& +\frac{1}{2}\left(1-\frac{1}{\psi}\right)\left(\frac{1}{\psi}-\gamma\right)\left(V_{t}\left[\log \widetilde{U}_{t+1}^{h}\right]-V_{t}\left[\log \widetilde{U}_{t+1}^{f}\right]\right) .
\end{aligned}
$$

In the main text we omit the difference of covariance terms to facilitate the discussion. From our simulations, this term can be shown to reinforce our results. The expected growth of the exchange rate takes the following form:

$$
\begin{aligned}
E_{t}\left[\Delta e_{t+1}\right] & =E_{t}\left[m_{t+1}^{f}-m_{t+1}^{h}\right] \\
& =\frac{1}{\psi}\left(E_{t}\left[\Delta c_{t+1}^{h}\right]-E_{t}\left[\Delta c_{t+1}^{f}\right]\right)+\frac{1}{2}(1 / \psi-\gamma)(1-\gamma) \cdot\left(V_{t}\left[\widetilde{U}_{t+1}^{h}\right]-V_{t}\left[\widetilde{U}_{t+1}^{f}\right]\right)
\end{aligned}
$$




\section{References}

Anderson, E., "The dynamics of risk-sensitive allocations," Journal of Economic Theory, 2005, 125(2), 93-150.

Backus, David and G. Smith, "Consumption and real exchange rates in dynamic exchange economies with nontraded goods.," Journal of International Economics, 1993, 35, 297316.

Bansal, R. and Ivan Shaliastovich, "A Long-Run Risks Explanation of Predictability Puzzles in Bond and Currency Markets," Working Paper, 2010.

Bansal, Ravi and Amir Yaron, "Risks for the Long Run: A Potential Resolution of Asset Pricing Puzzles,” 2004, 59, 1481-1509.

, Daka Kiku, and Amir Yaron, "Risks For the Long Run: Estimation and Inference.," Working Paper., 2010.

Colacito, Riccardo, "Six anomalies looking for a model. A consumption based explanation of international finance puzzles.," Working Paper, Department of Finance, University of North Carolina, Chapel Hill NC, 2008.

and Mariano M. Croce, "International Asset Pricing with Risk Sensitive Agents," Working Paper, Department of Finance, University of North Carolina, Chapel Hill NC, 2010.

and _ _ "The Short- and Long-Run Benefits of Financial Integration," The American Economic Review, 2010, 100(2), 527-31.

and _ , "Risks for the long run and the real exchange rate," Journal of Political Economy, 2011, 119(1), 153-182.

Cole, H. and M. Obstfeld, "Commodity trade and international risk sharing. How much do financial markets matter?," Journal of Monetary Economics, 1991, 28, 3-24.

Epstein, Larry G and Stanley E Zin, "Substitution, Risk Aversion, and the Temporal Behavior of Consumption and Asset Returns: A Theoretical Framework," Econometrica, July 1989, 57 (4), 937-69.

Fama, E., "Forward and spot exchange rates," Journal of Monetary Economics, 1984, 14, 319-338.

Hansen, Lars Peter and Ravi Jagannathan, "Implications of Security Market Data for Models of Dynamic Economies," Journal of Political Economy, 1991, 99, 225-262.

Lewis, Karen, "Trying to Explain Home Bias in Equities and Consumption," Journal of Economic Literature, 1999, 37, 571-608.

Lustig, Hanno and Adrien Verdelhan, "The Cross Section of Foreign Currency Risk Premia and Consumption Growth Risk," American Economic Review, 2007, 97, 89-117.

, Nikolai Roussanov, and Adrien Verdelhan, "Common Risk Factors in Currency Markets," Forthcoming in the Review of Financial Studies, 2011.

Mitchell, B.R., "International Hitorical Statistics: Europe," Macmillian Publishers Ltd, 2007. 
Obstfeld, Maurice, “The Global Capital Market: Benefactor or Menace?, Journal of Economic Perspectives, 1998, 12, 9-30.

Quinn, Dennis, “The Correlates of Change in International Financial Regulation," American Political Science Review, 1997, 91(3), 531-551.

Taylor, Alan, "International Capital Mobility in History: the saving-investment relationship," NBER Working Paper, 1996, 5743. 